\title{
Alternative techniques to reduce warm ischemia time in laparoscopic partial nephrectomy
}

Alexandre Stievano Carlos, Marcos Tobias-Machado, Eduardo Simão Starling, Felipe Brandão Corrêa de Araujo, Eliney Ferreira Faria, Lucas Nogueira, Roberto Vaz Juliano, Antonio Carlos Lima Pompeo

Department of Urology, ABC Medical School (ASC, MTM, ESS, FBCA, RVJ, ACLP), Santo Andre, Section of Urology, PIO XII Foundation, Cancer Hospital of Barretos (EFF), Barretos, SP and Department of Urology, Hospital das Clinicas, Federal University of Minas Gerais (LN), Minas Gerais, Brazil

\section{ABSTRACT}

Purpose: Demonstrate two alternatives that permit a warm ischemia time reduction during laparoscopic partial nephrectomy. Materials and Methods: In this video, two cases of intermediate complexity renal tumors according to the RENAL nephrometry renal scoring system illustrating the techniques and our preliminary experience: a 65 year old man with a $4 \mathrm{~cm}$ right, posterior renal tumor. This patient underwent an early unclamping and parenchymal suturing using a greek bar continuous suture with hem-o-lock clips attached to the respective extremities of the suture; The second patient is a 49 year old man with a $3 \mathrm{~cm}$ renal tumor. The technique utilized was no clamping resection following the ABC Medical School technique: dissection of renal hilum for eventual clamping if necessary, a frontal 360 degrees visualization of tumor limits, pneumoperitoneum pressure elevated to $25 \mathrm{mmHg}$ during tumor resection, spiral excavation of normal parenchyma around the tumor and resection with negative margins.

Results: We previously performed 15 cases utilizing the early unclamping technique. The mean clamp time was 15 minutes with a mean blood loss of $285 \mathrm{~mL}$. Only 1 patient had focal positive surgical margins, without recurrence demonstrated at 30 months. Fifteen partial nephrectomies were previously performed with on demand clamping. In 3 cases, clamping was necessary with a mean ischemia time of 11 minutes. The mean blood loss was $390 \mathrm{~mL}$ and 2 cases required a perioperative blood transfusion. One case presented with a positive focal margin without recurrence demonstrated at 24 months of follow-up. Renal function was preserved in all cases regardless of the technique applied.

Conclusion: Warm ischemia time can be reduced and kidney function can be preserved during laparoscopic nephrectomy if either early unclamping or on demand clamping are selectively applied.

\section{ARTICLE INFO}

Available at: www.brazjurol.com.br/videos/january_february_2013/Carlos_145_146video.htm

Int Braz J Urol. 2012; 39 (Video \#3): 145-6

Submitted for publication:

December 01, 2012

Accepted after revision:

January 30,2013
Correspondence address:

Dr. Alexandre Stievano Carlos

Cantagalo Street, 612 / 61

Sao Paulo, SP, Brazil

Fax: + 5511 2093-7434

E-mail: ale_carlos@uol.com.br 


\section{EDITORIAL COMMENT}

As nicely depicted in this video by Tobias-Machado et al., novel techniques of minimizing renal ischemia at time of partial nephrectomy are actively being thought. In the present video, two unique techniques are described: (1) early unclamping and parenchymal suturing using a greek bar continuous suture and (2) a non-clamping resection technique. These two specific approaches have been well characterized by others $(1,2)$. Although there are unique technical nuances adopted by the present authors pertaining to these techniques, it is important to highlight that the adoption of an early unclamping or non-ischemic nephron sparing surgical approach should for the most part be based on the features of the underlying renal tumor as it relates to the renal vasculature, proximity to the collecting system and likely anticipated extent of the renorrhaphy reconstruction, as well as its

\section{REFERENCES}

1. Abreu AL, Gill IS, Desai MM: Zero-ischaemia robotic partial nephrectomy (RPN) for hilar tumours. BJU Int. 2011; 108(6Pt2): 948-54.

2. Shao P, Tang L, Li P, Xu Y, Qin C, Cao Q, Ju X, Meng X, Lv Q, Li J, Zhang W, Yin C: Precise segmental renal artery clamping under the guidance of dual-source computed tomography angiography during laparoscopic partial nephrectomy. Eur Urol. 2012; 62: 1001-8. exophytic/endophytic location. Many of these mentioned characteristics are encompassed in current renal complexity scoring systems (e.g. nephrometry, PADUA, C-index). In addition, it is important to highlight that it is now well established that pre-operative renal function and the size of the tumor are the main determinants of post-operative renal function in a patient undergoing nephron sparing surgery $(3,4)$. Although ischemia time remains a modifiable variable which can impact post-operative renal function, it remains that it has a less important effect on long-term renal function within this surgical patient cohort than it was once believed. It nevertheless remains that techniques of minimizing renal ischemia should be encouraged and pursued using scientifically rigorous and reproducible techniques to ultimately optimize the surgical outcomes of our patients.
3. Simmons MN, Hillyer SP, Lee BH, Fergany AF, Kaouk J, Campbell SC: Functional recovery after partial nephrectomy: effects of volume loss and ischemic injury. J Urol. 2012; 187: 1667-73.

4. Thompson RH, Lane BR, Lohse CM, Leibovich BC, Fergany A, Frank I, et al.: Renal function after partial nephrectomy: effect of warm ischemia relative to quantity and quality of preserved kidney. Urology. 2012; 79: 356-60.

\author{
Dr. Philippe E. Spiess \\ Department of Genitourinary Oncology \\ Moffitt Cancer Center \\ Tampa, FL, USA \\ Video Section Editor, \\ International Brazilian Journal of Urology \\ E-mail: philippe.spiess@moffitt.org
}

